\title{
Analisis Kebutuhan Chemistry Games (CGs) pada Pembelajaran Kimia di SMA/MA Kota Pekanbaru
}

\author{
Ira Mahartika ${ }^{1}$, Neti Afrianis ${ }^{2}$, Nofri Yuhelman ${ }^{3}$ \\ 1,2 Program Studi Pendidikan Kimia, Universitas Islam Negeri Sultan Syarif Kasim Riau \\ ${ }^{3}$ Program Studi Pendidikan Kimia, Universitas Islam Kuantan Singingi \\ e-mail: \\ 1ira.mahartika@uin-suska.ac.id \\ ${ }^{2}$ netiafrianis23@gmail.com \\ 3nofriyuhelman@gmail.com
}

\begin{abstract}
.
This study aimed to comprehend the initial needs of chemistry games (CGs) media through field observation at Senior high schools in Pekanbaru. The data was processed quantitatively and used to determine the type of game that requires further development. This quantitative descriptive research used questionnaires and interviews for collecting data and used purposive sampling as a sampling technique. The number of respondents is 18 teachers and 140 students from 7 Senior high schools in Pekanbaru. The results showed: 1) The needs of learning media generally varies at each school; 42,86\% needs an electronic-based chemistry games media and 57,14\% needs both non-electronic and electronic-based chemistry games media, 2) Students demanded an instructional media that educational, interactive, exciting and fun, with a game form, 3) Teachers overwhelmed making an instructional teaching media.
\end{abstract}

Keywords : need assessment, instructional media of chemistry, chemistry game

\begin{abstract}
ABSTRAK.
Penelitian ini bertujuan untuk mendapatkan data kebutuhan media permainan kimia secara real melalui pengamatan dilapangan yang dilakukan pada SMA/MA di Kota Pekanbaru. Data yang didapatkan kemudian diolah secara kuantitatif dan digunakan sebagai pertimbangan untuk menentukan jenis permainan yang akan dikembangkan lebih lanjut. Penelitian ini merupakan jenis penelitian deskriptif kuantitatif. Teknik pengumpulan data yaitu melalui angket dan wawancara. Teknik sampling yang digunakan adalah purposive sampling sehingga didapatkan 7 sekolah SMA/MA di Kota Pekanbaru yang dijadikan sebagai sampel penelitian dengan jumlah guru sebanyak 18 orang dan siswa 140 orang. Temuan utama pada penelitian ini yaitu : 1) Kebutuhan media pembelajaran pada umumnya bervariasi pada setiap sekolah, 2) Siswa sangat menginginkan media pembelajaran yang edukatif, interaktif, menarik dan tidak membosankan yaitu salah satunya dengan sebuah permainan, 3) Guru memiliki keterbatasan waktu dalam membuat media pembelajaran.
\end{abstract}

Kata Kunci : analisis kebutuhan, media pembelajaran kimia, permainan kimia 


\section{PENDAHULUAN}

Permainan merupakan salah satu alternatif media pembelajaran yang saat ini telah banyak digunakan pada semua kalangan dalam bidang pendidikan. Permainan tersebut sering kita kenal dengan istilah permainan edukasi. Permainan edukasi ini tentunya banyak memiliki dampak positif yang ditimbulkan dalam sebuah jenis permainan. Seorang psikolog Evangeline I. Suaidy, M.Si dalam seminar "Coaching Clinic Kidzania" menyebutkan dampak positif permainan tersebut adalah selain memberikan wawasan, permainan ini juga mampu untuk melatih kerjasama, menstimulasi otak dan meningkatkan interaksi antar pemain (Kompas, 2012). Saat ini, dengan maraknya pengembangan teknologi tentunya tidak dapat dipungkiri bahwa permainan ini menjelma menjadi sebuah kebutuhan yang saat ini banyak dimainkan dan diminati oleh setiap kalangan. Hal ini terbukti dari banyaknya penelitian yang mengarah kepada pengembangan permainan yang memiliki manfaat dalam bidang pendidikan yang dikemas dalam bentuk teknologi digital/elektronik.

Penelitian terkait permainan pendidikan ini diantaranya telah dilakukan oleh Noemi yang meneliti tentang peranan permainan pendidikan dalam proses pembelajaran (Noemí \& Máximo, 2014). Oliveira dkk, membuat sebuah permainan visual dan kemudian memperkenalkannya kepada peserta didik dalam proses pembelajaran (Oliveira, Federal, Gomes, \& Junior, 2016). Maraffi dkk, mengembangkan sebuah permainan digital yang diberi nama "GeoQuest" dan sekaligus diterapkan dalam proses pembelajaran untuk meningkatkan hasil belajar para peserta didik (Sabina Maraffi, Francesco M. Sacerdoti, \& Eleonora Paris, 2017). Anastasiadis dkk, melihat dampak dari penerapan permainan digital dalam proses pembelajaran (Anastasiadis, Lampropoulos, \& Siakas, 2018). Brydges dan Dembinski mengembangkan permainan "Catalyze" dengan papan permainan yang mendukung untuk pemahaman siswa terhadap ilmu kimia secara lebih baik dan sukses (Brydges \& Dembinski, 2018). Berdasarkan kajian literatur tersebut dapat dibuktikan bahwa banyaknya para peneliti dari semua bidang yang tertarik dengan permainan sebagai objek kajian penelitiannya, baik itu tentang pengembangan permainan ataupun mengimplementasikannya dalam proses pembelajaran. Kemudian, tidak menutup kemungkinan bahwa pada bidang kimia juga banyak yang mengembangkan permainan dalam proses pembelajaran kimia.

Permainan pendidikan memiliki kelebihan dalam merangsang rasa ingin tahu peserta didik sehingga memotivasi mereka untuk belajar (Ang \& Rao, 2008). Vitianingsih juga menyatakan bahwa permainan pendidikan dapat mengembangkan kreativitas anak karena di dalam permainan tersebut memiliki unsur penalaran terhadap suatu materi, etika dan tantangan (Vitianingsih, 2016). Hidayat menyebutkan bahwa kelebihan permainan pendidikan berupa sebuah alat untuk mendukung proses belajar yang memungkinkan siswa untuk menghadapi tantangan, mempelajari berbagai perilaku, menerima risiko dari setiap tindakan yang menjadi tantangan pada permainan tersebut (Hidayat, 2018).

Pengembangan sebuah permainan tentunya tidak luput dari kegiatan analisis awal sebelum produk itu diciptakan. Kegiatan awal ini dikenal dengan istilah analisis kebutuhan (need assesment). Analisis kebutuhan merupakan suatu proses awal yang dilakukan untuk menyusun bahan ajar atau produk yang sesuai dengan kebutuhan siswa (Prastowo, 2010). Analisis kebutuhan ini juga disebut sebagai pondasi awal sebelum menciptakan sebuah produk agar tepat sasaran sesuai dengan tujuan yang akan dicapai serta sebagai dasar pertimbangan dalam memilih produk yang akan dikembangkan agar memiliki daya guna yang baik. Sesuai dengan pendapat Morisson dkk, menyatakan bahwa fungsi analisis kebutuhan yaitu sebuah alat untuk mengidentifikasi suatu masalah dan kemudian memilih intervensi yang cocok sesuai dengan kebutuhan (Morisson, Ross, \& Kemp, 2007). Berdasarkan kajian lapangan yang telah penulis lakukan bahwa rata-rata saat ini pengembangan sebuah produk tidak didasari oleh analisis kebutuhan yang baik dan detail. Hal ini terlihat saat penulis mewawancarai 15 orang mahasiswa pendidikan kimia yang mana penelitiannya tentang pengembangan produk media pembelajaran pada perguruan tinggi di kota Pekanbaru, didapatkan hasil bahwa produk yang telah dikembangkan hanya "tinggal kenangan" dan tidak dapat dimanfaatkan secara baik dalam proses pembelajaran. Beberapa produk yang mereka 
kembangkan diantaranya video pembelajaran, LKPD, modul, permainan edukasi dan blog edukasi. Penulis melakukan pengecekan pada karya ilmiah yang dimiliki ternyata analisis kebutuhan tidak dilakukan dengan baik dan detail, dan kajian literatur yang tidak mencukupi sehingga terkesan dipaksakan dalam memilih produk yang dikembangkan. Oleh sebab itu, data analisis kebutuhan sebaiknya dilakukan melalui kajian literatur dan kajian lapangan yang detail agar mendapatkan hasil yang tepat sasaran dan sesuai dengan tujuan.

Pernyataan yang telah dikemukakan tersebut diperkuat kembali dengan pengalaman penelitian pada tahun 2014 dan 2016, terdapat beberapa media pembelajaran yang dibuat oleh peneliti lain yang di uji coba pada lokasi penelitian yang sama saat menganalisis kebutuhan media tersebut. Hasil penelitian didapatkan bahwa media pembelajaran perlu perbaikan dan tidak sesuai dengan kebutuhan yang diinginkan oleh sekolah, guru dan peserta didik. Saat itu guru menginginkan sebuah media video pembelajaran pengganti laboratorium karena minimnya fasilitas labor disekolah tersebut, sehingga berdampak pada kompetensi dasar peserta didik tidak terpenuhi pada bagian praktikum, sedangkan media yang telah dibuat itu adalah video pembelajaran kimia sederhana yang hanya memuat materi pelajaran saja. Guru telah memberikan saran terkait media yang akan dibuat, tetapi tidak sesuai dengan yang diharapkan. Sehingga, masih terkesan dipaksakan dalam menentukan pilihan pembuatan media serta dilandasi pada kepentingan pribadi tanpa memikirkan kebutuhan yang diinginkan. Tentunya, hal ini diperkuat melalui pernyataan Arsyad yaitu pemilihan media didasarkan kepada tujuan dan sebaiknya dipilih menurut kemampuan dan kebutuhan (Arsyad, 2013).

Berdasarkan permasalahan yang telah dikemukakan, maka penulis tertarik untuk melakukan sebuah analisis kebutuhan khususnya untuk pengembangan media permainan pada mata pelajaran kimia, karena tidak menutup kemungkinan bahwa media permainan kimia juga membutuhkan sebuah analisis kebutuhan untuk memilih jenis permainan yang akan dirancang dan disesuaikan dengan kebutuhan dilapangan. Oleh sebab itu, perlu didapatkan informasi dari guru dan siswa tentang kebutuhan permainan pendidikan kimia serta persepsi tentang permainan pendidikan tersebut. Data pada penelitian ini dapat dijadikan sebagai panduan bagi peneliti lainnya untuk mengembangkan media pembelajaran dalam bentuk permainan kimia (prototype) yang memiliki daya guna serta bermanfaat. Penelitian ini nantinya juga memberikan kontribusi bagi penulis yaitu sebagai studi pendahuluan dalam pengembangan media permainan kimia untuk SMA/MA/SMK pada materi kimia.

\section{METODOLOGI}

Penelitian ini merupakan jenis penelitian deskriptif kuantitatif. Subjek penelitian yang terkait adalah guru dan siswa. Pemilihan sampel penelitian dilakukan dengan teknik purposive sampling, sehingga didapat 7 sekolah SMA/MA di wilayah kota Pekanbaru, 18 orang guru kimia dan 140 orang siswa. Teknik pengumpulan data menggunakan teknik non tes yaitu angket dan wawancara. Data primer dari wawancara yang didapatkan akan dideskripsikan secara rinci, kemudian data angket diolah secara kuantitatif (statistik). Waktu pelaksanaan penelitian ini berada pada bulan Juni - Agustus 2019.

Tahapan pelaksanaan penelitian ini terdiri dari 3 tahap, yaitu : 1) Tahap perencanaan, yang terdiri dari mengidentifikasi dan mendeskripsikan tentang target populasi dan responden yang terlibat dalam penelitian, mengklarifikasi tujuan analisis kebutuhan yaitu mendefinisikan masalah, mengidentifikasi sumber masalah dan menentukan solusi dari permasalahan, menetapkan cakupan dan tempat analisis kebutuhan, merancang instrumen penelitian yang meliputi panduan wawancara dan angket, proses pembuatan angket dan melakukan validasi instrumen dengan expert judgement. 2) Tahap pengumpulan data, mengumpulkan sumber informasi yang relevan dengan penelitian, mengumpulkan studi literatur terkait analisis kebutuhan media pembelajaran, melakukan proses penelitian dengan teknik pengumpulan data melalui wawancara dan angket, 
melakukan dokumentasi penelitian, membuat rekapitulasi informasi yang didapatkan selama penelitian. 3) Tahap analisis data dan interpretasi, melakukan review terhadap informasi yang telah dikumpulkan dengan anggota tim penelitian, melakukan analisis deskriptif dari hasil wawancara dan observasi penelitian, melakukan analisis kuantitatif dan membuat tabulasi dari hasil angket penelitian.

\section{TEMUAN DAN PEMBAHASAN}

Berdasarkan kesepakatan pada masing-masing sekolah, pada penjelasan ini nantinya penulis tidak mencantumkan nama sekolah melainkan hanya kode saja dikarenakan menghargai privasi suatu lembaga pendidikan, namun data pada penelitian ini real sesuai keadaan dilapangan yang dapat dijadikan sebagai pertimbangan bagi peneliti lain. Hasil penelitian yang telah didapatkan adalah sebagai berikut :

\section{Jenis Permainan Kimia}

Permainan kimia merupakan salah satu alternatif media pembelajaran yang digunakan dalam proses belajar mengajar. Permainan dapat membuat pembelajaran menjadi menyenangkan dan memiliki kebermaknaan yang tinggi jika diterapkan dengan metode pembelajaran yang tepat serta desain yang sesuai dengan tujuan pembelajaran yang ingin dicapai. Berbagai macam jenis permainan kimia yang saat ini telah diterapkan dalam proses pembelajaran kimia, berdasarkan hasil penelitian yang dilakukan jenis media permainan yang telah digunakan di 7 sekolah di kota Pekanbaru diantaranya molymod, permainan ice breaking, teka-teki silang, monopoli kimia, ludo, permainan ikatan kimia, kartu remi kimia, kartu berpasangan, puzzle, permainan ular tangga kimia, permainan online kahoot, permainan edukasi melalui android dan rangking 1. Berikut merupakan hasil data dari jenis permainan yang sudah dillakukan di sekolah sebagaimana dijelaskan pada tabel berikut:

Tabel 1. Rekapitulasi jenis permainan kimia

\begin{tabular}{cll}
\hline No & Kode Sekolah & \multicolumn{1}{c}{ Jenis Permainan Kimia } \\
\hline 1 & Sekolah A & $\begin{array}{l}\text { Molymod, kahoot, permainan melalui android, kartu } \\
\text { remi kimia, kartu berpasangan, teka-teki silang, } \\
\text { monopoli kimia }\end{array}$ \\
\hline 2 & Sekolah B & $\begin{array}{l}\text { Molymod, teka-teki silang, kartu remi kimia kartu } \\
\text { tebak gambar, ludo kimia, kahoot }\end{array}$ \\
\hline 3 & Sekolah C & $\begin{array}{l}\text { Molymod, permainan ice breaking, ular tangga, teka- } \\
\text { teki silang }\end{array}$ \\
\hline 5 & Sekolah E & Molymod, puzzle, kartu remi kimia \\
\hline 6 & Sekolah F & Molymod, kartu remi kimia, rangking 1, kahoot \\
\hline 7 & Sekolah G & $\begin{array}{l}\text { Molymod dari bahan plestisin, kartu berpasangan, } \\
\text { monopoli kimia }\end{array}$ \\
\hline
\end{tabular}

Jenis permainan yang telah dijelaskan diatas dominan merupakan ide dari guru kimia pada masing-masing sekolah, hal ini mereka lakukan karena tuntunan kurikulum yang mengharuskan para guru mampu untuk membuat media untuk proses pembelajaran. Agar lebih memperjelas para pembaca, maka peneliti membuat persentase jenis media yang dominan digunakan. Persentase tersebut dapat dilihat pada grafik dibawah ini : 


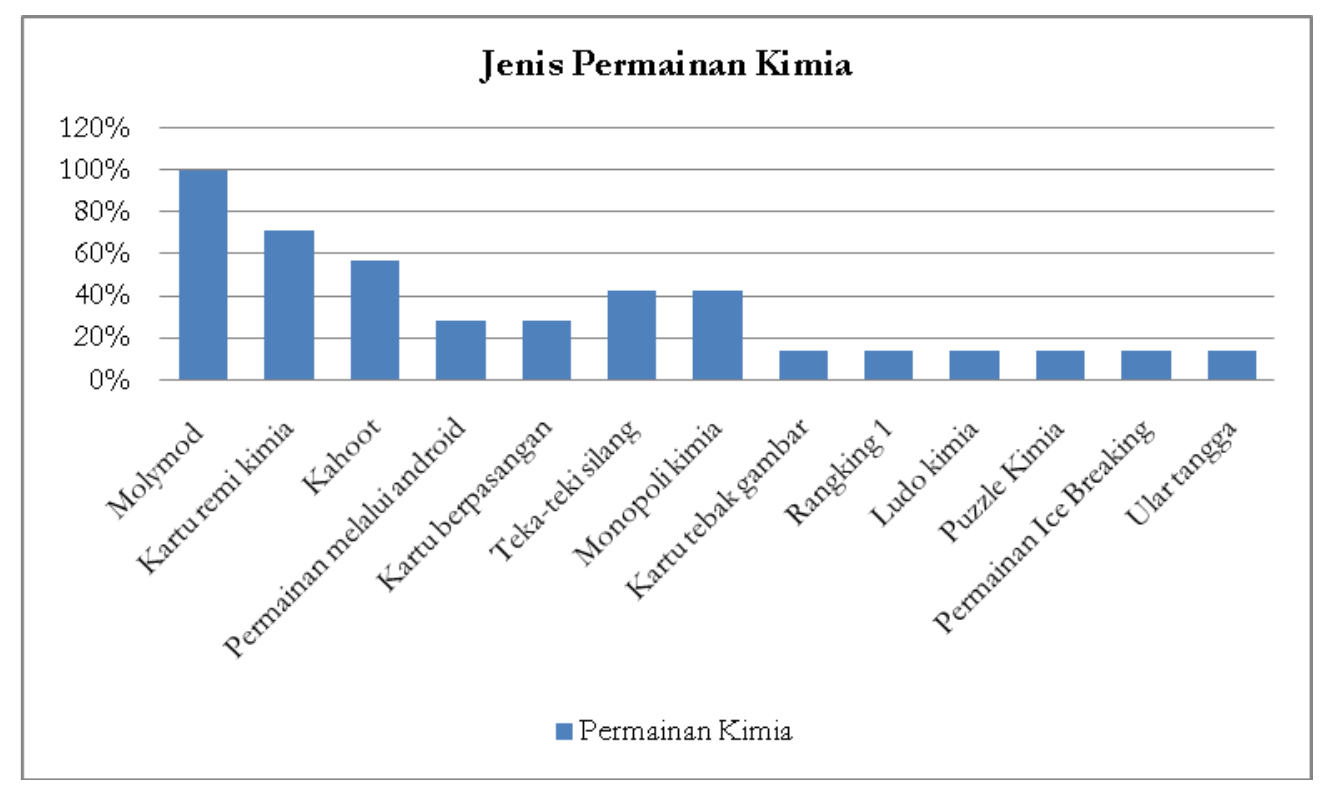

Gambar 1. Grafik rekapitulasi jenis permainan kimia

Berdasarkan grafik pada gambar 1. di atas menunjukkan bahwa permainan kimia secara keseluruhan telah digunakan di tujuh sekolah yang telah diteliti. Terdapat 5 jenis permainan kimia yang dominan digunakan dalam proses pembelajaran yaitu molymod, kartu remi kimia, kahoot, teka-teki silang dan monopoli kimia. Namun secara keseluruhan mereka telah menggunakan permainan molymod pada pembelajaran kimia khususnya pada materi hidrokarbon.

\section{Alasan Pemilihan Permainan Kimia yang Telah Digunakan}

Hasil wawancara yang dilakukan kepada guru kimia terkait alasan pemilihan permainan kimia di tujuh sekolah dapat dilihat pada tabel di bawah ini :

Tabel 2. Rekapitulasi hasil wawancara tentang alasan pemilihan permainan kimia

\begin{tabular}{clll}
\hline No & \multicolumn{1}{c}{ Responden } & \multicolumn{1}{c}{ Alasan Pemilihan Permainan Kimia } \\
\hline 1 & $\begin{array}{l}\text { Guru Kimia Sekolah A } \\
\text { (3 orang) }\end{array}$ & $\begin{array}{l}\text { Mengikuti perkembangan zaman dan disesuaikan dengan materi } \\
\text { pembelajaran, kemudian siswa sangat antusias jika pembelajaran dibarengi } \\
\text { dengan permainan dan rata-rata mereka sangat menyukai pembelajaran } \\
\text { visual. }\end{array}$ \\
\hline 2 & $\begin{array}{l}\text { Guru Kimia Sekolah B } \\
\text { (3 orang) }\end{array}$ & $\begin{array}{l}\text { Mengikuti perkembangan zaman dan disesuaikan dengan materi } \\
\text { pembelajaran, serta adanya kontribusi dari mahasiswa penelitian. }\end{array}$ \\
\hline 3 & $\begin{array}{l}\text { Guru Kimia Sekolah C } \\
\text { (2 orang) }\end{array}$ & $\begin{array}{l}\text { Disesuaikan dengan materi pembelajaran dan juga keadaan siswa agar } \\
\text { mereka tidak merasa jenuh. }\end{array}$ \\
\hline 4 & $\begin{array}{l}\text { Guru Kimia Sekolah D } \\
\text { (2 orang) }\end{array}$ & $\begin{array}{l}\text { Disesuaikan dengan materi pembelajaran dan juga mempertimbangkan } \\
\text { keadaan siswa di sekolah. }\end{array}$ \\
\hline 5 & $\begin{array}{l}\text { Guru Kimia Sekolah E } \\
\text { (3 orang) }\end{array}$ & $\begin{array}{l}\text { Disesuaikan dengan materi pembelajaran agar tidak monoton dengan } \\
\text { metode ceramah dan disesuaikan dengan kebutuhan siswa. }\end{array}$ \\
\hline 6 & $\begin{array}{l}\text { Guru Kimia Sekolah F } \\
\text { (3 orang) }\end{array}$ & $\begin{array}{l}\text { Disesuaikan dengan materi pembelajaran, kemudian guru saat ini dituntut } \\
\text { kreatif untuk menciptakan inovasi dalam pembelajaran. }\end{array}$ \\
\hline 7 & $\begin{array}{l}\text { Guru Kimia Sekolah G } \\
\text { (2 orang) }\end{array}$ & $\begin{array}{l}\text { Mengikuti perkembangan zaman dan disesuaikan dengan materi } \\
\text { pembelajaran, kemudian rata-rata siswa disini sangat menyukai belajar } \\
\text { sambil bermain. }\end{array}$ \\
\hline
\end{tabular}


Berdasarkan tabel 2. di atas menunjukkan bahwa alasan pemilihan media pembelajaran ini dominan adalah disesuaikan dengan materi pembelajaran karena tidak semua materi pembelajaran bisa sesuai dengan permainan kimia. Alasan lainnya yaitu banyaknya siswa yang sangat suka dengan permainan agar pembelajaran tidak monoton dan membosankan. Kemudian, harus disesuaikan dengan kebutuhan siswa itu sendiri. Bahkan ada juga guru yang menyatakan bahwa permainan dibuat sesuai dengan perkembangan zaman, ini terbukti pada sekolah A dan sekolah $G$ sudah membuat permainan berbasis android.

\section{Kendala Dalam Pemilihan dan Pembuatan Permainan Kimia}

Hasil wawancara kepada guru kimia terkait kendala dalam pemilihan dan pembuatan permainan kimia dapat dilihat pada tabel di bawah ini :

Tabel 3. Rekapitulasi hasil wawancara tentang kendala pemilihan dan pembuatan permainan kimia

\begin{tabular}{|c|c|c|}
\hline No & Responden & Tanggapan Guru \\
\hline 1 & $\begin{array}{l}\text { Guru Kimia Sekolah A ( } 3 \\
\text { orang) }\end{array}$ & $\begin{array}{l}\text { Membutuhkan waktu yang lama dalam } \\
\text { pembuatannya kemudian susah menemukan ide } \\
\text { jenis permainan agar dapat merangsang kemampuan } \\
\text { berpikir anak terhadap suatu materi pelajaran. } \\
\text { Permainan yang sering digunakan ini biasanya } \\
\text { dibantu oleh mahasiswa yang magang disini. }\end{array}$ \\
\hline 2 & $\begin{array}{l}\text { Guru Kimia Sekolah B (3 } \\
\text { orang) }\end{array}$ & $\begin{array}{l}\text { Membutuhkan waktu yang lama dalam proses } \\
\text { pembuatan dan ditambah lagi dengan kegiatan yang } \\
\text { sangat banyak disekolah. Sehingga, pembuatan } \\
\text { permainan ini sering dibantu oleh mahasiswa yang } \\
\text { magang dan penelitian. }\end{array}$ \\
\hline 3 & $\begin{array}{l}\text { Guru Kimia Sekolah C ( } 2 \\
\text { orang) }\end{array}$ & $\begin{array}{l}\text { Waktu dan biaya pembuatan permainan. sehingga } \\
\text { bahan yang digunakan hanya seadanya tetapi bisa } \\
\text { membuat permainan yang persis sama dengan } \\
\text { aslinya. Guru harus kreatif. }\end{array}$ \\
\hline 4 & $\begin{array}{l}\text { Guru Kimia Sekolah D ( } 2 \\
\text { orang) }\end{array}$ & $\begin{array}{l}\text { Sulit untuk menyesuaikan dengan materi pelajaran } \\
\text { dan mendorong siswa untuk berpikir terhadap } \\
\text { konsep materi yang diberikan melalui sebuah } \\
\text { permainan. }\end{array}$ \\
\hline 5 & $\begin{array}{l}\text { Guru Kimia Sekolah E ( } 3 \\
\text { orang) }\end{array}$ & $\begin{array}{l}\text { Membutuhkan waktu yang lama dan persiapan yang } \\
\text { matang, kecuali kahoot yang langsung bisa diakses } \\
\text { dan itupun harus menggunakan jaringan internet } \\
\text { agar berjalan dengan baik. Kondisi internet } \\
\text { disekolah ini masih dikhususkan untuk guru. }\end{array}$ \\
\hline 6 & $\begin{array}{l}\text { Guru Kimia Sekolah F (3 } \\
\text { orang) }\end{array}$ & $\begin{array}{l}\text { Sulit untuk menyesuaikan jenis permainan dengan } \\
\text { materi kimia yang bersifat teori dan hitungan, } \\
\text { sedangkan siswa disini kalau tidak ada permainan } \\
\text { mereka merasa jenuh. Sehingga guru termotivasi } \\
\text { untuk selalu berkarya dalam menciptakan produk } \\
\text { media pembelajaran. }\end{array}$ \\
\hline 7 & $\begin{array}{l}\text { Guru Kimia Sekolah G (2 } \\
\text { orang) }\end{array}$ & $\begin{array}{l}\text { Kesulitan terletak pada pembiayaan, tetapi selama ini } \\
\text { pembuatan permainan dibantu oleh mahasiswa } \\
\text { magang dan penelitian. }\end{array}$ \\
\hline
\end{tabular}

Berdasarkan tabel 3. di atas menunjukkan bahwa kendala yang selama ini dialami oleh guru yaitu pemilihan jenis permainan kimia yang harus disesuaikan dengan materi pelajaran agar dapat dipahami dengan baik serta mampu mendorong keterampilan berfikir siswa terhadap konsep yang diberikan melalui permainan tersebut. Kendala lainnya terdapat pada waktu dan biaya sehingga 
dalam pembuatannya dibantu oleh mahasiswa magang dan penelitian disekolah yang bersangkutan, kemudian bahan yang digunakan hanya seadanya tidak terlalu sama dengan bahan pada permainan aslinya. Sehingga dituntut sebuah ide dan kreatifitas dalam pembuatan permainan ini serta harus disesuaikan dengan tujuan pembelajaran yang akan dicapai.

\section{Tanggapan Peserta Didik Terhadap Permainan Kimia Yang Telah Digunakan}

Rekapitulasi hasil angket yang didapatkan dari peserta didik terkait tanggapan tentang permainan kimia dapat dilihat pada tabel di bawah ini :

Tabel 4. Rekapitulasi hasil angket tentang tanggapan peserta didik terhadap permainan kimia

\begin{tabular}{clll}
\hline No & \multicolumn{1}{c}{ Responden } & \multicolumn{3}{c}{ Tanggapan Peserta Didik } \\
\hline 1 & $\begin{array}{l}\text { Peserta Didik Sekolah A } \\
(20 \text { Orang) }\end{array}$ & $\begin{array}{l}\text { Permainan itu menyenangkan sehingga membuat } \\
\text { pembelajaran lebih luwes dan mudah dipahami. }\end{array}$ \\
\hline 2 & $\begin{array}{l}\text { Peserta Didik Sekolah B } \\
\text { (20 Orang) }\end{array}$ & $\begin{array}{l}\text { Permainan ini membuat semangat dalam } \\
\text { pembelajaran. }\end{array}$ \\
\hline 3 & $\begin{array}{l}\text { Peserta Didik Sekolah C } \\
\text { (20 Orang) }\end{array}$ & $\begin{array}{l}\text { Selama ini pembelajaran terlalu monoton, dengan } \\
\text { adanya permainan menjadi lebih asyik. }\end{array}$ \\
\hline 4 & $\begin{array}{l}\text { Peserta Didik Sekolah D } \\
\text { (20 Orang) }\end{array}$ & $\begin{array}{l}\text { Permainan itu seru dan menyenangkan serta } \\
\text { memudahkan dalam pemahaman materi. }\end{array}$ \\
\hline 5 & $\begin{array}{l}\text { Peserta Didik Sekolah E } \\
\text { (20 Orang) }\end{array}$ & $\begin{array}{l}\text { Belajar sambil bermain itu menyenangkan dan } \\
\text { membuat lebih fresh, selama ini pembelajaran } \\
\text { monoton dan banyak tugas sehingga dengan adanya } \\
\text { permainan bisa menjadi rileks. }\end{array}$ \\
\hline 6 & $\begin{array}{l}\text { Peserta Didik Sekolah F } \\
\text { (20 Orang) }\end{array}$ & $\begin{array}{l}\text { Dengan adanya permainan pembelajaran menjadi } \\
\text { bermakna dan tidak monoton. }\end{array}$ \\
\hline 7 & $\begin{array}{l}\text { Peserta Didik Sekolah G } \\
\text { (20 Orang) }\end{array}$ & $\begin{array}{l}\text { Permainan bisa menjadi alternatif disaat materi yang } \\
\text { begitu panjang dan susah memahaminya, sehingga } \\
\text { dengan permainan semuanya menjadi mudah untuk } \\
\text { dipahami. }\end{array}$ \\
\hline & &
\end{tabular}

Berdasarkan tabel 4. di atas menunjukkan bahwa media permainan ini memberikan suasana yang menyenangkan saat dimainkan dan membuat materi pelajaran mudah untuk dipahami. Temuan ini sesuai dengan pendapat yang dinyatakan oleh Law Nolte bahwa proses pembelajaran akan efektif jika dilaksanakan pada suasana pembelajaran yang menyenangkan (Dorothy Law Nolte, Dryden, \& Vos, 2000). Dalam hal ini, suasana pembelajaran yang menyenangkan dapat diciptakan melalui variasi metode pembelajaran dan pemilihan media pembelajaran yang menarik serta menantang peserta didik untuk memecahkan persoalan. Salah satu media pembelajaran yang dapat menciptakan suasana yang menyenangkan itu adalah permainan. Menurut Santrock permainan merupakan suatu aktivitas yang menyenangkan dan dilakukan untuk bersenang-senang (Santrock, 2007). Sehingga jika suasana menyenangkan itu muncul dalam proses pembalajaran, maka peserta didik akan termotivasi, minat terhadap pembelajaran pun semakin meningkat dan materi pelajaran akan mudah untuk dipahami.

\section{Jenis Permainan Yang Dibutuhkan Pada Mata Pelajaran Kimia}

Rekapitulasi jenis permainan yang dibutuhkan pada mata pelajaran kimia sesuai hasil wawancara dan angket yang diperoleh dari guru dan siswa dapat dilihat pada tabel di bawah ini : 
Tabel 5. Rekapitulasi jenis permainan yang dibutuhkan

\begin{tabular}{|c|c|c|c|}
\hline No & Responden & Guru & Siswa \\
\hline 1 & Sekolah A & $\begin{array}{l}\text { Permainan untuk materi hitungan } \\
\text { seperti stoikiometri, termokimia, } \\
\text { larutan penyangga, hidrolisis, laju } \\
\text { reaksi baik dalam bentuk elektronik } \\
\text { ataupun non elektronik. }\end{array}$ & $\begin{array}{l}\text { Permainan kimia dalam } \\
\text { bentuk digital/elektronik } \\
\text { seperti petualangan }\end{array}$ \\
\hline 2 & Sekolah B & $\begin{array}{l}\text { Permainan yang mampu membuat } \\
\text { siswa paham konsep kimia dalam } \\
\text { kehidupan baik dalam bentuk } \\
\text { elektronik ataupun non elektronik.. }\end{array}$ & $\begin{array}{l}\text { Permainan kimia dalam } \\
\text { bentuk digital/elektronik } \\
\text { ataupun non elektronik }\end{array}$ \\
\hline 3 & Sekolah C & $\begin{array}{lcc}\text { Permainan } & \text { yang } & \text { bisa } \\
\text { menggambarkan } & \text { molekul } & \text { dan } \\
\text { ikatannya dengan jelas. } & \end{array}$ & $\begin{array}{l}\text { Permainan kimia dalam } \\
\text { bentuk digital/elektronik } \\
\text { ataupun non elektronik }\end{array}$ \\
\hline 4 & Sekolah D & $\begin{array}{l}\text { Permainan untuk materi bersifat } \\
\text { hafalan seperti menghafal sistem } \\
\text { periodik unsur pada semua } \\
\text { golongan baik dalam bentuk } \\
\text { elektronik ataupun non elektronik.. }\end{array}$ & $\begin{array}{l}\text { Permainan kimia dalam } \\
\text { bentuk digital/elektronik } \\
\text { ataupun non elektronik }\end{array}$ \\
\hline 5 & Sekolah E & $\begin{array}{l}\text { Permainan yang } \\
\text { memperkenalkan hakikat ilmu } \\
\text { kimia dan konsep hitungan pada } \\
\text { kimia baik dalam bentuk elektronik } \\
\text { ataupun non elektronik.. }\end{array}$ & $\begin{array}{l}\text { Permainan kimia dalam } \\
\text { bentuk digital/elektronik }\end{array}$ \\
\hline 6 & Sekolah F & $\begin{array}{l}\text { Permainan yang dapat membantu } \\
\text { dalam memahami konsep dan } \\
\text { hitungan kimia baik dalam bentuk } \\
\text { elektronik ataupun non elektronik.. }\end{array}$ & $\begin{array}{l}\text { Permainan kimia dalam } \\
\text { bentuk digital/elektronik }\end{array}$ \\
\hline 7 & Sekolah G & $\begin{array}{l}\text { Permainan yang mampu } \\
\text { mendorong keterampilan siswa } \\
\text { dalam mengembangkan kognitif } \\
\text { dan keterampilan siswa, baik dalam } \\
\text { bentuk elektronik ataupun non } \\
\text { elektronik.. }\end{array}$ & $\begin{array}{l}\text { Permainan kimia dalam } \\
\text { bentuk digital/elektronik } \\
\text { ataupun non elektronik }\end{array}$ \\
\hline
\end{tabular}

Berdasarkan tabel 5. di atas menunjukkan bahwa terdapat perbedaan kebutuhan antara guru dan siswa, namun masih memiliki kesamaan pada jenis permainan dalam bentuk elektronik ataupun non elektronik. Jenis permainan juga tidak disebutkan secara detail, akan tetapi gambaran permainan yang dibutuhkan adalah mengacu kepada materi pelajaran kimia yang bersifat konsep dan hitungan, sehingga nantinya diharapkan melalui permainan tersebut materi kimia dapat dipahami dengan baik dan bersifat long term memory. Berdasarkan hasil wawancara di atas, maka persentase kebutuhan media permainan kimia pada 7 sekolah yang telah diteliti yaitu sebanyak 42,86\% menginginkan media permainan dalam bentuk elektronik dan 57,14\% membutuhkan kedua jenis media permainan dalam bentuk elektronik ataupun non elektronik

Keterbatasan penelitian ini khusus pada permainan pendidikan di mata pelajaran kimia SMA/MA. Pengambilan sampel dilakukan berdasarkan berbagai pertimbangan, sehingga didapatkan sampel di 7 kecamatan dari 12 kecamatan yang ada di Kota Pekanbaru diantaranya kecamatan Lima Puluh, Payung Sekaki, Marpoyan Damai, Tampan, Senapelan, Sukajadi dan Tenayan Raya. Penelitian selanjutnya akan mengarah kepada media pembelajaran secara umum agar data yang didapatkan lebih komprehensif. 


\section{SIMPULAN}

Berdasarkan hasil penelitian secara keseluruhan didapatkan bahwa permainan merupakan salah satu media pembelajaran yang berkontribusi dalam menciptakan suasana belajar yang efektif. Sekolah saat ini rata-rata sudah pernah menerapkan kegiatan belajar sambil bermain dan siswa merasa senang dan tertarik dalam mempelajari ilmu kimia yang selama ini terkesan sulit dan membosankan melalui permainan. Hal ini dibuktikan dari banyaknya antusias siswa dalam menanggapi penggunaan media pembelajaran dengan menyatakan bahwa pembelajaran menjadi menyenangkan dan mudah untuk dipahami. Siswa sangat menginginkan jika permainan dikembangkan dalam bentuk elektronik/digital sesuai dengan perkembangan teknologi saat ini. Guru juga menginginkan permainan yang mengacu kepada materi pelajaran kimia yang bersifat konsep dan hitungan, sehingga siswa dapat memahami materi tersebut melalui permainan. Oleh sebab itu, penelitian ini dapat dijadikan referensi bagi peneliti lain dalam menciptakan produk pengembangan permainan pada mata pelajaran kimia SMA/MA yang ada di Kota Pekanbaru.

\section{PENGHARGAAN}

Penulis mengucapkan terimakasih kepada Kepala Sekolah yang telah memberikan kesempatan kepada penulis untuk melakukan penelitian di sekolah yang bapak/ibu pimpin, selanjutnya kepada para Guru dan Siswa yang telah berkontribusi dalam memberikan data secara detail dan valid terkait penelitian ini, serta kepada tim internal penulis yang telah membantu dalam mengumpulkan dan menganalisis data penelitian ini.

\section{REFERENSI}

Abdul Rahman, R., Mohammad Yusof, Y., Kashefi, H., \& Baharum, S. (2012). Developing mathematical communication skills of engineering students. Procedia-Social and Behavioral Sciences, 46, 5541-5547.

Ahmad, F. A. (2012). Philosophical Underpinnings of Islamic Management Method: Worldview, Epistemology and Ontology. International Journal of Humanities and Social Science, 2(20), 150 161.

Ang, C. S., \& Rao, G. S. R. K. (2008). Computer game theories for designing motivating educational software: A survey study. International Journal on E-Learning, 7(2), 181-199.

Anastasiadis, T., Lampropoulos, G., \& Siakas, K. (2018). Digital Game-based Learning and Serious Games in Education. International Journal of Advances in Scientific Research and Engineering, 4(12), 139-144.

Arsyad, Azhar. (2013). Media pembelajaran. Jakarta: Rajawali Press.

Brydges, S., \& Dembinski, H. E. (2018). Catalyze! Lowering the Activation Barriers to Undergraduate Students ' Success in Chemistry: A Board Game for Teaching Assistants. Jourmal of Chemical Education, 96(3), 511-517.

Dorothy Law Nolte., Dryden., \& Vos. (2000). Revolusi Cara Belajar. Terjemahan Word Translation Service, Bandung: Kaifa.

Kompas.com. (2012, 03 September). Manfaat Positif Main "Game" untuk Anak. Diakses pada $20 \quad$ Januari $2020, \quad$ dari https://tekno.kompas.com/read/2012/09/03/11470652/manfaat.positif.main.quotgamequ ot.untuk.anak.

Hanapi, M. S. (2013). The Conceptual Elements of the Development Worldview in the Qur'an: A Study of Thematic Exegesis. American International Journal of Social Science, 2(3), 40-55. 
Hidayat, R. (2018). Game-Based Learning: Academic Games sebagai Metode Penunjang Pembelajaran Kewirausahaan. Buletin Psikologi, 26(2), 71-85.

John W. Santrock (2007). Perkembangan anak. Jakarta: Erlangga.

Morrison., Ross., \& Kemp. (2007). Designing effective instruction 5th edition. Hoboken: Willey and Sons inc.

Noemí, P.-M., \& Máximo, S. H. (2014). Educational games for learning. Universal Journal of Educational Research, 2(3), 230-238.

Oliveira, W., Federal, S. U., Gomes, C., \& Junior, S. (2016). An Introduction to Educational Games Virtualization An Introduction to Educational Games Virtualization. (September).

Prastowo, Andi. (2010). Panduan kreatif membuat bahan ajar inovatif. Yogyakarta: Diva Pers.

Sabina Maraffi, Francesco M. Sacerdoti, \& Eleonora Paris. (2017). Learning on Gaming: A New Digital Game Based Learning Approach to Improve Education Outcomes. US-China Education Review A, 7(9), 421-432.

Vitianingsih, A. V. (2016). Jurnal llmiah Bidang Teknologi lnformasi dan. Jurnal INFORM, 1(1), 25-32 